\title{
Advanced method for station point control accuracy to monitor the behaviour in service stage of civil engineering structures using geodetic satellite technology
}

\author{
Diana-Ioana Morariu, Daniel Lepadatu
}

\begin{abstract}
The monitoring of important engineering buildings is mandatory and necessary especially in crowded urban areas. Achieving a stable and optimal monitoring network leads to a more effective time monitoring of objectives through the use of satellite methods. Satellite geodetic technology along with emerging technologies is a modern way to get data on civil buildings monitored with reasonable accuracy. Thus, the fast evolution of communication technologies allowed and developed several satellite constellations throughout the Globe at the same time, depending on the needs and economic power of owners. In the present scientific paper, we will describe an analysis of the accuracy of data obtained with the use of satellite technology for monitoring the behavior of an engineering building using Romanian Positioning System (ROMPOS) based on satellite systems such as: Global Navigation Satellite System (GNSS), Russian GLONASS and European Galileo, but also on GNSS permanent stations, obtaining real-time data in the ETRS89 European Coordinate System. The aim of this paper is to compare the use of the Global Positioning System (GPS) and GLObalnaya NAvigatsionnay Sputnikovaya SistemaGLONASS, Chinese Navigation Satellite System - BeiDou, both individually and simultaneously to determine the control points of the monitoring network. The precision of station points determining for an engineering structure is important, and in the case of the use of satellite technology it can be influenced by multiple factors that will be presented in the paper. The accuracy of the station coordinates of the selected target is given by integrating both satellite constellations by increasing the number of satellites used, obtaining a more accurate position with greater visibility to them. It is an engineering structure, viaduct type, over 50 years old, with a length of 1.3 kilometers. The objective is in the North-West part of Galati, Romania and represents an important access road connecting Galati city to the platform of ArcelorMittal steel company requiring a regular observationeven a permanent monitoring.
\end{abstract}

Keywords-GPS, GLONASS, Bei Dou, Civil Engineering, monitoring behaviour in service stage, station points control.

Ioana Diana Morariu and Daniel Lepadatu,

"Gh. Asachi" Technical University of Iaşi,

Faculty of Civil Engineering and Building Services

Country: ROMANIA

\section{Introduction}

The monitoring of engineering buildings behaviour in service stage is a extremely complex process and requires special monitoring tools. Surveying equipments with the evolution of technology and society have seen a significant development which includes among others the use of renewable energy (I. Alecu et all, 2014). The determination of spatial displacements of engineering structures is currently done using modern methods, among which we can list the satellite technology (D.I. Morariu, and D. Lepadatu, 2017).

Global Positioning System dates back to the Sputnik era when researchers used radio signal changes to track satellites, a phenomenon called "Doppler effect". At the beginning of the 1970 's, the Department of Defense (D.O.D) from Unitated States of America (U.S.A) wanted to provide a stable satellite navigation system. The first satellite navigation system launched in 1978 is called NAVigation System with Timing And Ranging (NAVSTAR). It has become fully operational in 1993. The GPS now offers two levels of service: The Standard Positioning Service (SPS) that uses the pseudo-random code (C/A) on L1 frequency and the Precision Positioning Service uses the precise code $\mathrm{P}(\mathrm{Y})$ with frequency L2. NAVSTAR constellation includes 32 satellites, of which only 31 are functional (D. Lepadatu, 2016) (D. Lepadatu, et all. 2014) (R. Abdulmajed, and R.A. Abbak, 2017) (J. Neuner, 2000).

Instead, GLObalnaya NAvigatsionnay Sputnikovaya Sistema (GLONASS) became partially available after the collapse of the Soviet Union. Since February 2017, the satellite system is not at full capacity but is kept in constant mode and remains operational with 21 satellites (D. Lepădatu, 2016, a) (D. Lepadatu, et all , 2014) (J. Neuner, 2000).

On the other hand, the Galileo European System is connected to the GPS / NAVSTAR and GLONASS satellite constellation to provide a high precision of determination of point positioning. The reference and coordinate system used is ETRS89 (European Terrestrial Reference System), consisting of 30 satellites. The Galileo System is considered superior to the GPS (Figure 1) because it provides horizontal and vertical measurements with a precision of 1 meter (D. Lepadatu, 2016) (D. Lepadatu, D. Covatariu, L. Judele, G. Săndulache, A.R. Roșu, M. Diac, 2014) (J. Neuner, 2000).

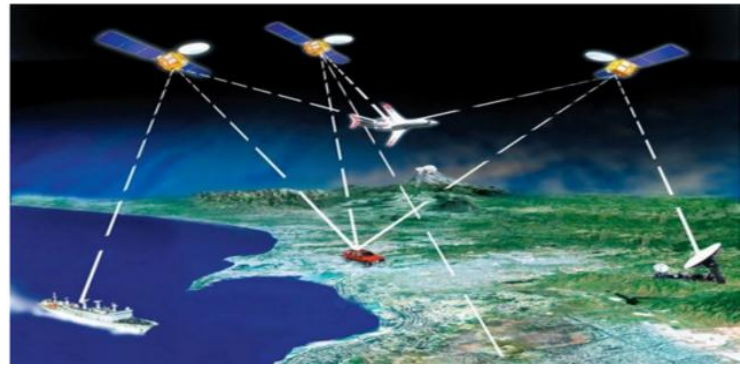

Figure 1. GPS System [5] 
The Chinese Satellite Navigation System is called BeiDou (BDS). It consists of two separate constellations. The first is called Experimental Navigation System through Satellite BeiDou or BeiDou-1 and contains three satellites offering limited coverage of navigation services. The constellation was withdrawn in 2012.

The second generation of the BeiDou Navigation System (BDS), also known as COMPASS or BeiDou-2, became operational in China in December 2011 with a partial constellation of 10 satellites in orbit. Provides services to Asia-Pacific customers (Lepadatu D., 2016, a).

In 2015, China began building the third generation (BeiDou-3) in the global constellation. The first BDS-3 satellite was launched on March 30, 2015. Since January 2018, nine BeiDou-3 satellites have been launched. BeiDou3 will have 35 satellites and will provide global services at its completion in 2020. After complete accomplishment, BeiDou will provide a global satellite navigation system to the Global Positioning System (GPS) and is expected to be more accurate than GPS.

The Global Positioning System in Romania is represented by ROMPOS (the Romanian Determination Position System) and has been developed by the National Agency for Cadastre and Real Estate Advertising (ANCPI). The institution has carried out the modernization of permanent measuring stations based on GNSS (Global Navigation Satellite System) satellites, thus forming permanent GNSS stations. The signals they receive are GPS (U.S.A), GLONASS (RUSSIA) and in the future will be the European GALILEO. The system was launched in 2008, providing the necessary informations to determine the realtime position of 0.5 meters (Lepadatu D., 2016, a).

The advantages of using the three satellite constellations while reading the position of a point can be: availability of a larger number of satellites, satellite geometry is improved, the determination of a point is made more precisely and with greater accuracy, avoiding signal loss.

In the following section it will be described the method of determining the position of the control points of the monitoring network in time of the behaviour of the chosen objective using satellite technology.

Also, it will be presented the accuracy of the satellite system for each determined control point using each constellation individually, as well as by associating them. Finally, the advantages and disadvantages of the method used to monitor the chosen objective will be discussed.

\section{Satellite method for monitoring behavior in service stage}

Monitoring behaviour in service stage by topographic methods using the satellite technique from thi present scientific paper will be done for a engineering structure viaduct type. The objective is the longest viaduct (Figure 2, 3 ) in Romania. Built between 1968-1970 on 15 high pillars (Figure 4) of 60 meters high, it has experienced from the beginning multiple settlings due to the swampy ground on which it was built.

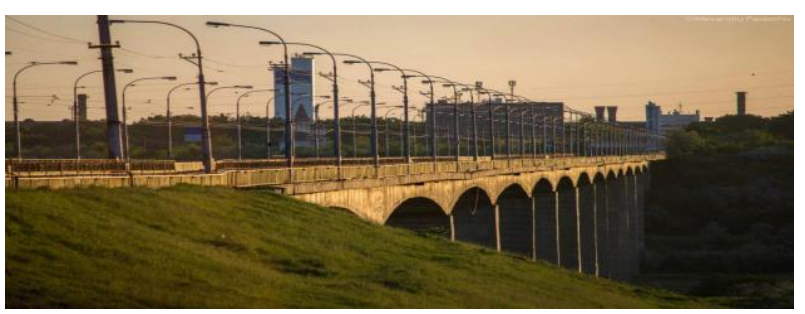

Figure 2. Viaduct - Combinatului Street

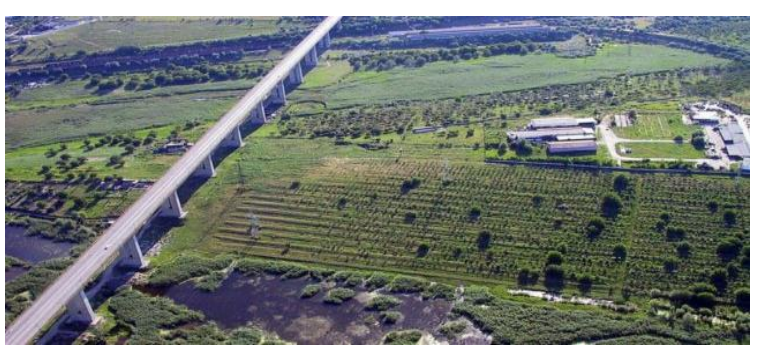

Figure 3. Viaduct - sky view

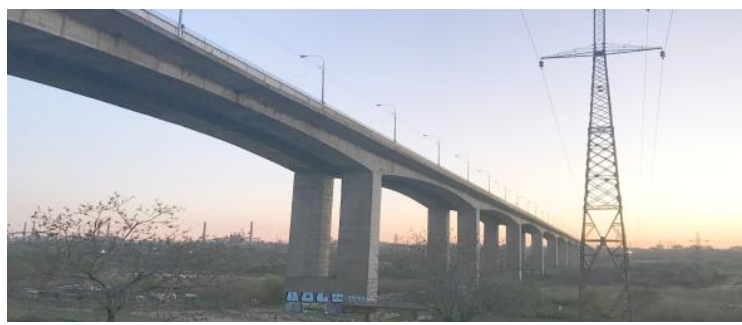

Figure 4. Viaduct - pillar view

Vertical spatial displacements were produced also due to the significant earthquakes of 1977, 1986 and 1990, but also to the heavy traffic that caused the structure to weaken. Therefore, the permanent monitoring of the objective is recommended to be done by using modern and accurate surveying methods (Lepadatu et all. 2016, b).

We are proposing a monitoring behaviour in service stage network made up of monitoring marks on the viaduct, control points, station points from which we will read the vertical movements of the structure and the orientation points with known coordinates. The location of the viaduct marks (Figure 5) are placed at the ends of the objective joints at approximately 150 meters from each other on both sides of the structure. The monitoring marks are in number by two at the end of the joint on one side and the other. The total number of landmarks on the viaduct is 40 markers.

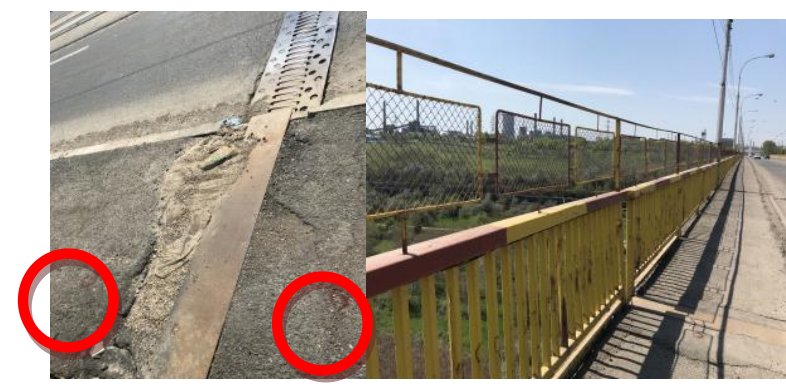

Figure 5. Location of the marks on the viaduct

Control points (P1, P2..., P7) (Figure 6) will be determined using GPS technology. The determination of each control point will be done by reading the NAVSTARGPS, GLONASS, BeiDou system individually and all together. 
Proc. of Eighth International Conference On Advances in Civil, Structural and Mechanical Engineering - ACSM 2018

Copyright (C) Institute of Research Engineers and Doctors, USA. All rights reserved.

ISBN: 978-1-63248-154-2 doi: 10.15224/978-1-63248-154-2-12

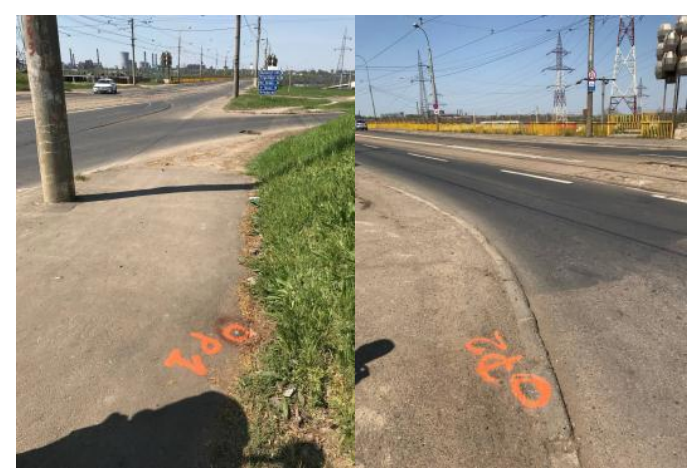

Figure 6. Control points

Thus, the accuracy of each constellation will be obtained and we will be able to choose the most accurate position of the point. They will be located outside the viaduct 's area of influence so as to ensure visibility between the network's control points and the station points from which we will read the marks on the objective.

The instrument used to measure the control points is GPS RTK Stonex S10 (Figure 7a, b). The GPS Receiver has a number of 220 channels, can simultaneously receive GPS L1 C / A, L2 E, L2 C, L5, Glonass L1 C / A, L1 P, L2 C / A (Glonass M) SBAS concurrently L1 C / A, L5, Galileo E1, ESA, E5B (reserved) and Bei Dou 2 / Compass: B1, B2.
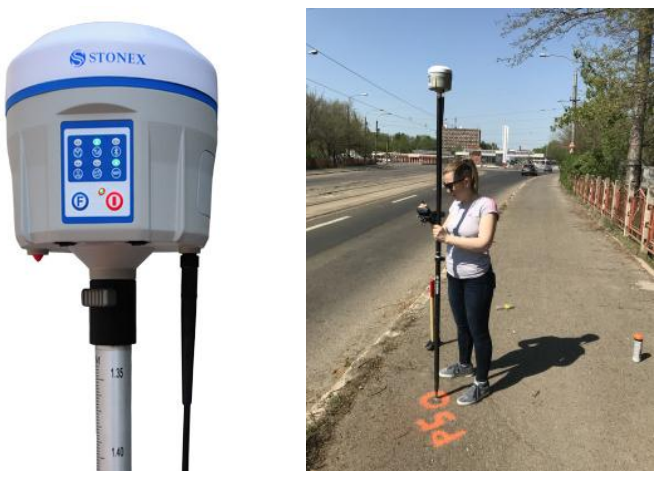

Figure 7 a) GPS RTK Stonex S10 b) GPS RTK Stonex S10 with accesories

The accuracy of the static horizontal reading is $2.5 \mathrm{~mm}+$ $0.1 \mathrm{ppm}$, static vertical: $3.5 \mathrm{~mm}+0.4 \mathrm{ppm}$, horizontal RTK in fixed solution: $8 \mathrm{~mm}+1 \mathrm{ppm}$, vertical RTK in fixed solution: $15 \mathrm{~mm}+1 \mathrm{ppm}$ and DGPS: Horizontal $0.25 \mathrm{~m} /$ Vertical $0.45 \mathrm{~m}$.

The station points and monitoring marks will be determined using the modern digital total station Leica TCR 805 Power (Figure 8).

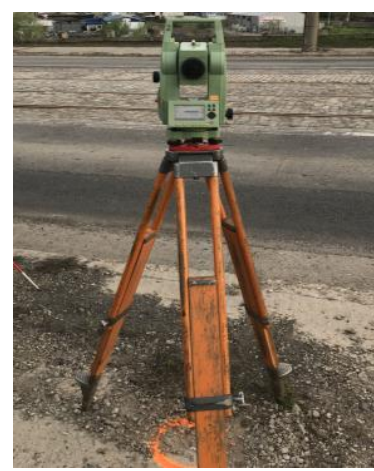

Figure 8. Total Station - Leica TCR 805 Power

The device has a precision of 1 " for measuring angles with a 5" accuracy, $1.5 \mathrm{~mm}$ precision for distance reading, the maximum sighting distance with prism is 3500 meters and a dual electronic axis for reading compensation.

Along with getting a precise and clearly determined position in real-time of the control points, the station points will have a plain location of known coordinates and improved results will be obtained in the monitoring process of the structure. Thereby, efficiency is achieved on monitoring in time in terms of precision, time, costs and number of operators.

\section{Results and discussions}

The monitoring in time network of the viaduct consists of the control points P1, P2, ..., P7 determined with GPS RTK Stonex S10 and the monitoring marks R1, R2, ... R40 read with Leica TCR 805 total station by the resection method. The station points on which the equipment was placed were chosen according to the visibility to the marks and to read as many of them as possible in order to optimize the monitoring process in time.

Stationing in each control point (P1, P2,..., P7) I read the positions of the points with the following constellations: GLONASS, NAVSTAR-GPS, BeiDou and all satellites listed simultaneously (Figure 9).

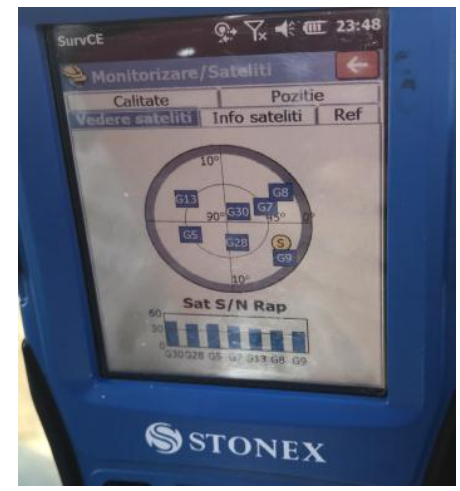

Figure 9. Satellites during measurement process

RTK precision positioning of the monitoring in time network points was achieved using the Network Transport of RTCM via Internet Brăila Protocol (NTRIP Brai_3.1), a permanent GNSS network.

Control point determinations were made by stationing on each point for one minute with a number of 10 readings. The distance between points P1, P2, ...., P7 is located between 30 and 140 meters (Figure $10 \mathrm{a}, \mathrm{b}$ ).

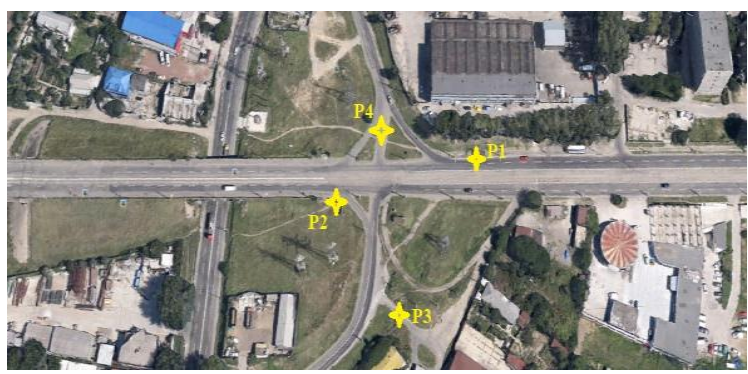

Figure 10. a) Point location P1-P4 
Proc. of Eighth International Conference On Advances in Civil, Structural and Mechanical Engineering - ACSM 2018 Copyright (C) Institute of Research Engineers and Doctors, USA. All rights reserved.

ISBN: 978-1-63248-154-2 doi: 10.15224/978-1-63248-154-2-12

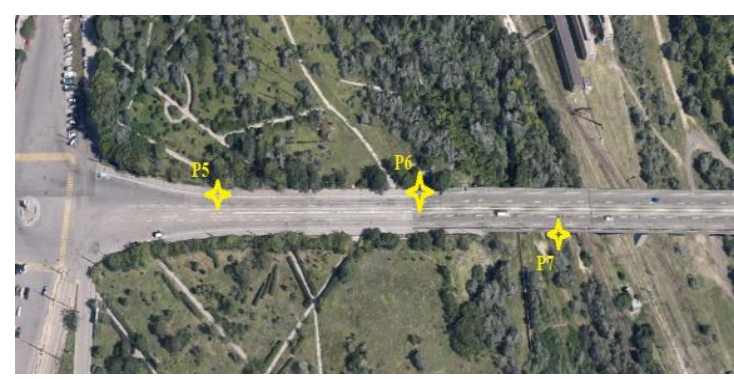

b) Point location P5-P7

Table 1 shows the coordinates of the control points determined with all satellite constellations, as well as the errors on the three directions $\mathrm{X}, \mathrm{Y}$ and $\mathrm{Z}$ on the constellations of the individual satellites NAVSTAR-GPS, GLONASS, Bei Dou.

TABLE 1. DIFFERENCES BETWEEN SIMULTANEOUS AND INDIVIDUAL DETERMINATIONS

\begin{tabular}{|c|c|c|c|c|c|}
\hline $\begin{array}{c}\text { Point } \\
\text { No. }\end{array}$ & Coordinates[m] & \multicolumn{2}{|c|}{$\begin{array}{c}\text { NAVSTAR- } \\
\text { GPS }\end{array}$} & GLONASS & BeiDou \\
\hline \multirow{4}{*}{ P1 } & 442301.006 & $\Delta \mathrm{X}$ & 1.281 & 0.016 & 0.043 \\
\cline { 2 - 6 } & 735489.268 & $\Delta \mathrm{Y}$ & -0.448 & -0.002 & -0.011 \\
\cline { 2 - 6 } & 45.219 & $\Delta \mathrm{Z}$ & -0.716 & 0.038 & 0.114 \\
\hline \multirow{4}{*}{ P2 } & 442280.766 & $\Delta \mathrm{X}$ & 0.210 & -0.004 & -0.024 \\
\cline { 2 - 6 } & 735420.742 & $\Delta \mathrm{Y}$ & -0.023 & -0.005 & 0.005 \\
\cline { 2 - 6 } & 44.784 & $\Delta \mathrm{Z}$ & 0.012 & 0.011 & 0.031 \\
\hline \multirow{4}{*}{ P3 } & 44230.678 & $\Delta \mathrm{X}$ & -0.003 & 0.015 & -0.001 \\
\cline { 2 - 6 } & 735449.661 & $\Delta \mathrm{Y}$ & 0.030 & -0.010 & -0.011 \\
\cline { 2 - 6 } & 43.269 & $\Delta \mathrm{Z}$ & 0.038 & -0.022 & 0.025 \\
\hline \multirow{4}{*}{ P4 } & 442314.226 & $\Delta \mathrm{X}$ & -0.007 & 0.023 & 0.016 \\
\cline { 2 - 6 } & 735442.889 & $\Delta \mathrm{Y}$ & 0.025 & -0.024 & -0.021 \\
\cline { 2 - 6 } & 44.320 & $\Delta \mathrm{Z}$ & -0.005 & 0.011 & 0.018 \\
\hline \multirow{3}{*}{ P5 } & 442289.462 & $\Delta \mathrm{X}$ & 0.069 & -0.009 & -0.047 \\
\cline { 2 - 6 } & 734019.291 & $\Delta \mathrm{Y}$ & 0.014 & -0.035 & 0.002 \\
\cline { 2 - 6 } & 54.712 & $\Delta \mathrm{Z}$ & -0.001 & -0.027 & 0.036 \\
\hline \multirow{3}{*}{ P6 } & 442290.161 & $\Delta \mathrm{X}$ & 0.022 & -0.026 & -0.038 \\
\cline { 2 - 6 } & 734140.187 & $\Delta \mathrm{Y}$ & 0.010 & -0.013 & 0.004 \\
\cline { 2 - 6 } & 54.084 & $\Delta \mathrm{Z}$ & -0.026 & 0.026 & 0.076 \\
\hline \multirow{3}{*}{ P7 } & 442274.482 & $\Delta \mathrm{X}$ & 0.032 & -0.022 & -0.023 \\
\cline { 2 - 6 } & 734160.839 & $\Delta \mathrm{Y}$ & 0.014 & 0.001 & 0.008 \\
\cline { 2 - 6 } & 54.241 & $\Delta \mathrm{Z}$ & 0.008 & 0.020 & 0.023 \\
\hline \multirow{3}{*}{} & & & & & \\
\hline
\end{tabular}

It can be noticed that the accuracy of NAVSTAR-GPS determinations varies between 0.001-1.280 meters of readings with all constellations. The high values for the three directions for point $\mathrm{P} 1$ are due to the location of the point near high trees that obstructed the signal from the satellites. This error can be solved by using the modern digital total station, by reading P1 from other point well determined with GPS tool with resection method. On the other hand, the BeiDou determinations are at a difference of 0.001-0.114 meters from the simultaneous measurements. Also, the time for measuring with BeiDou was very high due to the status of each point, that took long to reach a fixed position. The best accuracy is achieved by the GLONASS constellation, since the differences between the simultaneous and the individual are close: 0.001-0.038 meters.

Differences in the determination of individual and simultaneous satellite constellations occur due to errors influenced by satellite disposition in orbit, atmospheric conditions, satellite visibility, errors in electronic's receiver, instrument's antenna, tropospheric refraction, ionospheric refraction, orthogonal errors and the number of satellites available during reading the point as detailed in Table 2.

TABLE 2. NUMBER OF SATELLITES FOR DETERMINING CONTROL POINTS

\begin{tabular}{|c|c|c|c|c|}
\hline $\begin{array}{c}\text { Point } \\
\text { No. }\end{array}$ & $\begin{array}{c}\text { NAVSTAR- } \\
\text { GPS }\end{array}$ & GLONASS & BeiDou & Simultaneous \\
\hline P1 & 8 & 13 & 8 & 14 \\
\hline P2 & 7 & 14 & 9 & 15 \\
\hline P3 & 7 & 14 & 9 & 15 \\
\hline P4 & 7 & 13 & 8 & 13 \\
\hline P5 & 8 & 14 & 7 & 14 \\
\hline P6 & 8 & 15 & 8 & 15 \\
\hline P7 & 8 & 16 & 9 & 17 \\
\hline
\end{tabular}

Table 2 shows the number of satellites with which the control points of the viaduct monitoring network were obtained. One can notice the constellation GLONASS with a large number of satellites and all three simultaneous constellations. This improves the precision of the position of the points, but also the value of the errors decreases.

Factors that must be taken into account when you use GPS technology and may lead to errors are:

1. base length;

2. the number of visible satellites;

3. satellite constellation geometry;

4. signal/noise ratio for satellite signal (Signal to Noise Ratio - SNR) (Lepadatu D. et all., 2014).

Errors that may occur during the measurement process with satellite techniques may be accentuated by GPS receivers through the following parameters shown in Table 3:

1. Position Dilution of Precision - PDOP

2. Horizontal Dilution of Precision - HDOP

3. Vertical Dilution of Precision - VDOP.

TABLE 3. PARAMETERS USED TO ESTIMATE GPS ACCURACY

\begin{tabular}{|c|c|c|c|c|c|}
\hline $\begin{array}{c}\text { Point } \\
\text { No. }\end{array}$ & \multicolumn{2}{|c|}{$\begin{array}{c}\text { NAVSTAR- } \\
\text { GPS }\end{array}$} & GLONASS & BeiDou & Simultaneous \\
\hline \multirow{4}{*}{ P1 } & PDOP & 2.0665 & 1.6283 & 3.486 & 1.2064 \\
\cline { 2 - 6 } & HDOP & 1.2000 & 0.9000 & 1.700 & 0.7000 \\
\cline { 2 - 6 } & VDOP & 1.6824 & 1.3570 & 3.043 & 0.9826 \\
\hline \multirow{4}{*}{ P2 } & PDOP & 2.1558 & 1.4516 & 1.4522 & 1.2207 \\
\cline { 2 - 6 } & HDOP & 1.2000 & 0.8000 & 0.8000 & 0.7000 \\
\cline { 2 - 6 } & VDOP & 1.7910 & 1.2112 & 1.2120 & 1.0001 \\
\hline \multirow{4}{*}{ P3 } & PDOP & 2.1475 & 1.4384 & 1.4472 & 1.2276 \\
\cline { 2 - 6 } & HDOP & 1.2000 & 0.8000 & 0.8000 & 0.7000 \\
\cline { 2 - 6 } & VDOP & 1.7810 & 1.1954 & 1.2060 & 1.0085 \\
\hline \multirow{4}{*}{ P4 } & PDOP & 2.0899 & 1.6225 & 2.0665 & 1.4879 \\
\cline { 2 - 6 } & HDOP & 1.2000 & 0.9000 & 1.2000 & 0.8000 \\
\cline { 2 - 6 } & VDOP & 1.7110 & 1.3500 & 1.6824 & 1.2545 \\
\hline \multirow{3}{*}{ P5 } & PDOP & 1.6954 & 1.3950 & 1.7144 & 1.4994 \\
\cline { 2 - 6 } & HDOP & 1.0000 & 0.7000 & 1.0200 & 0.8400 \\
\cline { 2 - 6 } & VDOP & 1.3684 & 1.2065 & 1.3730 & 1.2414 \\
\hline \multirow{3}{*}{ P6 } & PDOP & 1.7192 & 1.2349 & 1.4917 & 1.2440 \\
\cline { 2 - 6 } & HDOP & 1.0000 & 0.6400 & 0.8400 & 0.6100 \\
\cline { 2 - 6 } & VDOP & 1.3984 & 1.0552 & 1.2320 & 1.0839 \\
\hline \multirow{3}{*}{ P7 } & PDOP & 1.7156 & 1.2007 & 1.5238 & 1.1636 \\
\cline { 2 - 6 } & HDOP & 1.0000 & 0.6000 & 0.8000 & 0.6000 \\
\cline { 2 - 6 } & VDOP & 1.3940 & 1.0400 & 1.2954 & 0.9970 \\
\hline \multirow{4}{*}{} & & & & & \\
\hline & & & & \\
\hline
\end{tabular}


The PDOP values determined with NAVSTAR GPS for points $\mathrm{P} 1, \mathrm{P} 2, . . ., \mathrm{P} 7$ vary between $1-2$ meters, which is an excellent efficiency. The same can be said about GLONASS and the values performed with all constellations. Instead, for BeiDou, the PDOP falls between 1-3 meters, indicating a good but not ideal efficiency.

In conclusion, a good accuracy is obtained with the constellation GLONASS, but it is ideal with all satellite constellations due to the excellent PDOP, VDOP and HDOP parameters, but also the large number of satellites received during the measurements and the good visibility between them.

\section{Conclusions}

In this scientific paper we have determined the accuracy of control points using the satellite method to monitor the behavior in service stage of a civil engineering structure of viaduct type.

In this context, the measurements were made using a GPS tool using the simultaneous connection of the satellite constellations and the individual choice.

The results showed that in terms of good visibility, unobstructed by climatic conditions, high buildings or trees, the signal received by GPS had better performance, reliability and availability. Following the studies on the values of each type of individual and combined constellations, the positions of the control points were obtained.

The ideal accuracy for the control points was determined using the GLONASS satellites, but also by the combined use of the constellations available by the receiver used. Thus, an increase in data quality, stability of control points, prevention of signal loss and combined and simultaneous availability of satellites are achieved.

Also, by determining the position of the control points as accurately as possible, Leica TCR 805 total station was set on the points obtained in real-time with the GPS technology, gaining a very good accuracy over the monitoring marks of the objective. Monitoring the behaviour of buildings in time through modern digital surveying methods implies the achievement of an optimal system in terms of accuracy, time and cost.

\section{Acknowledgments}

This paper is part of my phd thesis Optimization methods for monitoring in service stage of civil engineering structure behaviour at the "Gheorghe Asachi" Technical University of Iasi, Faculty of Civil Engineering and Building Services. I would like to thank Eng. Viorel Tomşa for his willingness to help me with the GPS tool in the study and the measurements. I would also like to thank Eng. Marcel Pacioglu for his help during the measurements with the total station.

This work was supported by a mobility grant of the Romanian Ministery of Research and Innovation, CNCS UEFISCDI, project number PN-III-P1-1.1-MC-2018-1052, within PNCDI III.

\section{References}

[1] R. Abdulmajed, R.A. Abbak, "Accuracy comparison between GPSonly and combined GPS plus GLONASS", Asian Journal of Science and Technology, Vol. 08, Issue, 11, pp.6563-6566, November, 2017.

[2] R.M. Alkan, I.M. Ozulu, "Accuracy Comparison of PPP Using GPSonly and Combined GPS+GLONASS Satellites in Urban Area: A Case Study in Çorum", Journal of the Arab Institute of Navigation, Vol.32, pp 7-12, 2015.

[3] S. Choy, S. Zhang, F. Lahaye, P. Héroux, "Acomparison between GPS-only and combined GPS+GLONASS Precise Point Positioning", Journal of Spatial Science, Vol. 58, No. 2, pp.169-190, 2013.

[4] D. Lepadatu, D. Covatariu, L. Judele, G. Săndulache, A.R. Roșu, M. Diac, "Spatial co-ordinates optimization of civil engineering and building services faculty's topographic network using gps technology", Scientific Papers, Agronomy series, Vol.57 (2), pp.113116, 2014.

[5] D. Lepadatu, "Topography for young constructors", Eds. Matei-Teiu Botez, Jassy, Romania, 2016.

[6] D. Lepadatu, L. Judele, G. Săndulache, A.R Roşu, M. Diac, "Evolution of distance measurement techniques by optical or optoelectronics way in applied topography", Proceedings of Symposium on Agriculture and Food Engineering, published in Scientific Works - Agronomy Series, no. 57(2), Jassy, Romania, pp.107-112., 2014.

[7] D.I. Morariu, D. Lepadatu., " Topo-geodetic modern methods and techniques for building monitoring process", The International Symposium of Agriculture and Food Engineering, Water and Soil Section, Jassy, Romania, Vol 60, no.2, pp. 139-144, 2017.

[8] D.I. Morariu, D. Lepadatu, "Geodetic monitoring of buildings in service stage and identification of structural degradation causes" The International Symposium Geomat 2017 ", Geodesy and Cartography Section, Engineering Geodetic Measurements, Photogrammetry and Remote Sensing, Jassy, Romania, 23-24 November 2017.

[9] D.I Morariu, D. Lepadatu, "Advanced tools for optimization and efficiently monitoring behavior in service stage of buildings using renewable energy ", The International Conference „Advanced Concepts in Mechanical Engineering - ACME 2018”, Jassy, Romania, 7-8 June 2018.

[10] J. Neuner, "Systems of Global Positioning, Eds. Matrix Rom, Bucharest, 2000.

[11] D.I. Morariu, Evolution of optical and optical-electronic instruments for angle measurements, University Creations, $10^{\text {th }}$ National Symposyum of Jassy, June 2017.

[12] L. Wei, C. Wang, "GPS in the tailings dam deformation monitoring", First International Symposium on Mine Safety Science and Engineering, Beijing, China, 2011.

[13] I. Alecu C. Bofu, I. Craciun, C. R. Giurma-Handley, I. Antonescu, M. Telisca, C. Boariu, "Correlation between Green Energy Cadastre and Environmental Monitoring", Journal of Environmental Protection and Ecology, , 15(4), 1751-1758, 2014.

[14] Lepadatu, D., Judele, L., Sandulache, G., et al. (2016). Civil Engineering and Building Service Topographic Permanent Landmarks Network. Spatial Coordinate Optimization. Present Environment and Sustainable Development, 10(1), pp. 171-178. Retrieved 10 May. 2018, from doi:10.1515/pesd-2016-0015

About Author (s):

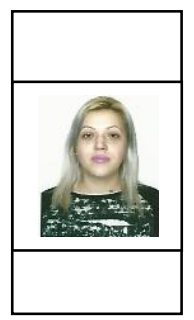

Morariu Diana Ioana is phd student at Faculty of Civil Engineering and Building Services, Technical University Gheorghe Asachi, of Iasi. Interested in modern technology in surveying area, monitoring buildings techniques and renewable energy.

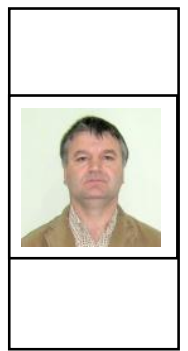

Daniel Lepadatu is senior lecturer at Technical University Gh. Asachi Iasi Romania, Faculty of Civil Engineering and Building Services. His major interest in research area are design of experiments and processes optimization using modern methods - response surface methodology and neural networks. 